\title{
Correspondence
}

We welcome letters to the Editor concerning articles which have recently been published. Such letters will be subject to the usual stages of selection and editing; where appropriate the authors of the original article will be offered the opportunity to reply.

Letters should normally be under 300 words in length, double-spaced throughout, signed by all authors and fully referenced. The edited version will be returned for approval before publication.

\section{Percutaneous repair of the ruptured tendo Achillis}

Sir

We read with interest the article by Webb and Bannister ${ }^{1}$ in the September 1999 issue describing a modification to the technique of percutaneous repair of tendo Achillis which is intended to reduce the risk of injury to the sural nerve. We agree that a prospective study comparing this with other standard techniques is essential to determine its role in the management of rupture of tendo Achillis.

They describe a regime of six weeks in a cast after operation. Several other studies ${ }^{2-7}$ have shown that functional treatment with early movement using dynamic bracing does not compromise the operative repair and produces results which are better than those of immobilisation of the ankle. Functional treatment allows earlier return to work and sporting activities with higher patient satisfaction. We believe this to be the optimum method of postoperative management of the repaired tendo Achillis. Adherence to an outdated regime may make it more difficult to demonstrate the benefits of any new surgical method. Perhaps it may be possible for these authors to take account of this in their further studies.

S. DEAKIN, MSc, FRCS

J. WOOD, BSc, SROT

J. L. BARRIE, FRCS Orth

Blackburn Royal Infirmary

Blackburn, UK.

1. Webb JM, Bannister GC. Percutaneous repair of the ruptured tendo Achillis. J Bone Joint Surg [Br] 1999;81-B:877-80.

2. Buchgraber A, Pässler HH. Percutaneous repair of Achilles tendon rupture: immobilisation versus functional postoperative treatment. Clin Orthop 1997;341:113-22.

3. Carter TR, Fowler PJ, Blokker C. Functional postoperative treatment of Achilles tendon repair. Am J Sports Med 1992;20:459-62.

4. Cetti R, Henriksen LO, Jakobsen KS. A new treatment of ruptured Achilles tendons: a prospective randomised study. Clin Orthop 1994;308:155-65.

5. Mandelbaum BR, Myerson MS, Forster R. Achilles tendon ruptures: a new method of repair, early range of movement and functional rehabilitation. Am J Sports Med 1995;23:392-5.

6. Mortensen NHM, Jensen PE. Early motion of the ankle after operative treatment of a rupture of the Achilles tendon: a prospective, randomised, clinical and radiographic study. J Bone Joint Surg [Am] 1999;81-A:983-90

7. Solveborn S, Moberg A. Immediate free ankle motion after surgical repair of acute Achilles tendon ruptures. Am J Sports Med 1994;22:605-10.

(C)2000 British Editorial Society of Bone and Joint Surgery 0301-620X/00/311045 \$2.00

J Bone Joint Surg [Br] 2000;82-B:461-4.

\section{Author's reply:}

Sir,

We thank Messrs Deakin, Wood and Barrie for their interest.

We agree that functional bracing is now established as a proven technique for early mobilisation after repairs of tendo Achillis. We began using the new percutaneous repair in 1992, however, when functional bracing was only just becoming established.

We are currently carrying out a randomised, controlled trial, comparing percutaneous repair and the non-operative management of acute ruptures of tendo Achillis. We have recruited 70 patients to date and both groups have functional bracing in their rehabilitation programme. The non-operative group begins controlled mobilisation of the ankle after 2.5 weeks and patients in the operative group, who have had a percutaneous repair, are braced one week after surgery.

We hope to present the results of this trial within the next year.

J. M. WEBB, FRCS Orth

North Bristol NHS Trust

Bristol, UK.

\section{Work practice and histopathological changes in the tenosynovium and flexor retinaculum in carpal tunnel syndrome in women}

Sir,

It is with some concern that I read the conclusions of the article by Chell, Stevens and Davis ${ }^{1}$ entitled 'Work practice and histopathological changes in the tenosynovium and flexor retinaculum in carpal tunnel syndrome in women' in the September 1999 issue. While I acknowledge the difficulties in producing any research on the subject of occupation in relation to disorders of the upper limb which will stand up to rigorous scientific appraisal, I do not believe that the conclusions stated can be drawn from the research undertaken.

There are a number of deficiencies. First, it would appear that the group of patients in which there may have been a relationship between high force with repetition and the presence of carpal tunnel syndrome numbered only seven. In the other group in which an association would not be expected there were 51. I believe that this imbalance seriously flaws the conclusion.

Secondly, careful review of the results seems to confirm the contention that in certain circumstances repetitive, forceful acts can lead to tenosynovitis, which in turn can give rise to carpal tunnel syndrome. For example, the authors report the case of a horse handler in whom they found a marked inflammatory cell infiltrate. Also, they note that certain non-occupational yet repetitive acts can aggravate symptoms in carpal tunnel syndrome, examples being knitting, sewing and gardening, and they report an association between these hobbies and the presence of tenosynovial fibrosis. I would, however, remind them that many people earn their living undertaking such activities.

Finally, chronology is of the essence in work-related disorders of the upper limb. While this may seem somewhat pedantic the authors make no mention of any time lag between cessation of working and surgery. If this time period is sufficiently long it may well be that any inflammatory response has subsided. 
It is commonly stated that there is very little scientific evidence to show that any work activity can produce problems in the upper limb. While I would agree with this I also believe that the converse is true, more specifically that there is no evidence that they do not. The authors are to be congratulated in their attempts at bringing some science to this difficult area but I do not believe that they have added anything further to our knowledge at this time.

I. A. TRAIL, MD, FRCS

Wrightington Hospital for Joint Disease

Wigan, UK.

1. Chell J, Stevens A, Davis TRC. Work practices and histopathological changes in the tenosynovium and flexor retinaculum in carpal tunnel syndrome in women. J Bone Joint Surg [Br] 1999;81-B:868-70.

\section{Authors' reply:}

Sir,

We thank Mr Trail for his interest in our paper. We agree that there were few cases in the high force/high-repetition group, but this reflects the work practices of women. Those tasks which are believed by some doctors to cause carpal tunnel syndrome in women were well represented in the study.

To investigate whether heavy manual work influences the histopathology of the carpal tunnel would require a similar study of men, and this is presently ongoing.

The case of the horse handler in whom there was no resolution of symptoms after carpal tunnel release was highlighted since this was the only example of the presence of an inflammatory cell infiltrate. It is possible that there was a different underlying pathology, such as a mild inflammatory arthropathy, and we urge $\mathrm{Mr}$ Trail not to place excessive importance on this isolated instance. We also appreciate that some individuals may earn a living from their hobbies, but this did not apply to the population studied. We are unable to explain why there was an association between certain hobbies and tenosynovial fibrosis, but not between work content and this factor.

All the women studied were doing their normal work until the time of surgery and complained of persisting symptoms. Therefore we hope that any histopathological change due to work practices was still present.

Finally, we disagree with Mr Trail's opinion that our study has not added anything further to our knowledge of the influence of work on the carpal tunnel syndrome in women. It has shown that myxoid degeneration of the flexor retinaculum may be influenced by work, but that this has no obvious effect on the tenosynovium.

J. CHELL, FRCS Ed (T\&O)

T. R. C. DAVIS, FRCS

Queen's Medical Centre

Nottingham, UK.

\section{Disarticulation at the ankle using an anterior flap}

Sir,

We read with interest the article in the July 1999 issue entitled 'Disarticulation at the ankle using an anterior flap' and wish to make the following observations.

Over a period of nine years, we have performed disarticulation of the ankle using an anterior flap after primary radical debridement in 42 patients needing amputation of the foot following injury by land mines. The wound healed in two weeks without any complications in all patients. They were mobilised using a cylindrical bootee for walking indoors in the third week. After 1 to 1.5 months a plastazote pad was placed on the stump for the fitting of a prosthesis. When walking outdoors the patients used a prosthesis which combined partial end-bearing and partial weight-bearing on the patellar tendon. Ground contact and standing without a prosthesis were also acceptable. Early fitting of the prosthesis made it unnecessary to open a window on the socket and it was easier to accommodate the slender stump. We did not encounter problems of the flap slipping from the stump as may be seen in a conventional Syme amputation. All the patients were satisfied with their prosthesis. Ankle disarticulation with an anterior flap rather than transtibial amputation should be used in patients with amputation of the foot as a result of injury since a conventional Syme amputation cannot be undertaken when there are injuries to the heel.

S. ATESALP, MD

C. YILDIZ, MD

Gülhane Military Medical Academy

Ankara, Turkey.

1. Robinson KP. Disarticulation of the ankle using an anterior flap: a preliminary report. J Bone Joint Surg [Br] 1999;81-B:617-20.

\section{Author's reply:}

Sir,

We thank Drs Atesalp and Yildiz for their comments. The patients reported in our paper with one exception were elderly and one further 74-year-old patient has been treated with a satisfactory result. It is pleasing to hear that younger patients also have a satisfactory outcome in terms of healing and function.

The prostheses supplied to our patients all had a fitted sleeve liner, which is a plunge fit in a resin socket, with mixed end and patellar-tendon weight-bearing. Since the length of the stump is slightly less than that of the conventional Syme amputation, it allows space for a multiaxial ankle mechanism. For the younger patient gait and function are particularly important and the comparison with a transtibial amputation and patellar-tendon-bearing prothesis will be crucial. In the elderly the ability to stand and take a few steps indoors without any prosthesis is perhaps a more important consideration.

K. P. ROBINSON, MS, FRCS

Queen Mary's Hospital

London, UK.

\section{Plain radiography in the degenerate knee}

Sir,

We read with interest the paper in the July 1999 issue by A. P. Davies et al entitled 'Plain radiography in the degenerate knee: a case for change'. While it is clear from the radiographs that the posteroanterior view in $30^{\circ}$ of flexion shows more significant changes, we wonder if this actually altered the management of any of their patients. The decision to offer total joint arthroplasty should be made on the basis of symptoms and informed consent, not radiographs alone, no matter how severe the radiological changes.

A. G. SUTHERLAND, FRCS Ed (T\&O)

A. R. BAKER, FRCS

Department of Orthopaedic Surgery

University of Aberdeen

Aberdeen, UK. 
1. Davies AP, Calder DA, Marshall T, Glasgow MMS. Plain radiography in the degenerate knee: a case for change. J Bone Joint Surg [Br] 1999;81-B:632-5.

Author's reply:

Sir,

We thank Mr Sutherland and Mr Baker for their interest in our paper. The management of any orthopaedic patient is of course based on a thorough history, complete examination and appropriate investigations. We would not and did not suggest otherwise. As a profession we are privileged to be able to request investigations involving radiation exposure to our patients. It behoves us to request the investigations which provide the most useful information for the least radiation exposure. Exchanging the fully-extended weight-bearing posteroanterior radiograph for a weightbearing view in $30^{\circ}$ of flexion achieves this objective.

A. P. DAVIES, MRCS

Norfolk \& Norwich Health Care NHS Trust

Norwich, UK.

\section{Biomechanical comparison of fixation of type-I fractures of the lateral tibial plateau}

Sir,

I read with interest the paper by Parker et al $^{1}$ in the May 1999 issue entitled 'Biomechanical comparison of fixation of type-I fractures of the lateral tibial plateau'.

The authors concluded that adding an antiglide screw or a third lag screw did not provide any biomechanical advantage in stabilising type-I fractures of the lateral tibial plateau, but they did appreciate that the results may have been biased in that the tibiae tested were from elderly donors. I believe that another possibility should be considered. In specimens 2 and 11, the yield loads in the tibiae of the treatment group were obviously lower than those of the control group. It is likely that this was caused by factors other than the additional screw, such as the differing bone quality of the two tibiae of the same subject. Although these factors may affect the other pairs, it does not mean that the interfering elements are balanced in the two groups. One method of decreasing the effects of the interfering elements is to abandon the special values after careful analysis. Interestingly, when I omitted specimens 2 and 11, I drew a completely opposite conclusion in that the differences were both statistically significant $(\mathrm{p}<0.05)$. Another method of balancing the interfering elements is to increase the number in the sample and to draw a reliable conclusion; a larger sample is therefore needed.

J. W. TAN, MD

The Institute of Traumatology and Orthopaedics of Shandong Province Qingdao, People's Republic of China.

1. Parker PJ, Tepper KB, Brumback RJ, Novak VP, Belkoff SM. Biomechanical comparison of fixation of type-I fractures of the lateral tibial plateau. J Bone Joint Surg [Br] 1999;81-B:478-80.

\section{Authors' reply:}

Sir,

We thank Dr Tan for his comments on our paper.

We agree that adding more specimens to our study would have increased the statistical power and may have resulted in the ability to show significant differences between the treatment groups. A power analysis suggested 263 paired tibiae may have given sufficient statistical power to show significance, but obtaining these for this purpose would be a phenomenal waste of resources.

More importantly, however, is the issue of clinical significance. Even if we had removed specimens 2 and 11 from our data set, there would still be a maximum mean difference between the treatment groups of only $147 \mathrm{~N}$. Although removing these specimens may have resulted in statistically significant differences between groups, $147 \mathrm{~N}$ is at most one-third of the body-weight, hardly a clinically significant increase in the weight-bearing capacity of the repair. Furthermore, culling specimens from a data set is highly inappropriate, particularly if based on speculated differences in bone density between right and left tibiae from a given donor. We are unaware of any reports in the literature which suggest that there are such differences in bone density. We did not measure bone density and therefore cannot comment on the role that it may have played in our results. Our specimens were harvested from elderly donors and therefore the bone density and strength were likely to be lower than those from a younger population. The weakness of conducting experiments in vitro on cadaver tissue is that the donor population is typically elderly. The only way to establish definitively whether or not adding a third screw is effective in repairing fractures of the tibial plateau is by carrying out a randomised, prospective study in vivo. Our in vitro biomechanical study suggests that if such a study were done and a difference found, it is likely to be clinically irrelevant.

\section{P. J. PARKER, MD}

K. B. TEPPER, MD

R. J. BRUMBACK, MD

V. P. NOVAK, MS

S. M. BELKOFF, PhD

R. Adams Cowley Shock Trauma Centre

Baltimore, USA.

\section{Screw versus suture fixation of Mitchell's osteotomy}

Sir,

We read with interest the paper in the July 1999 issue by Calder, Hollingdale and Pearse ${ }^{1}$ entitled 'Screw versus suture fixation of Mitchell's osteotomy'.

There were two main differences between the study groups, namely the method of fixing the osteotomies and the postoperative management. We suggest that the latter was the main determinant of the result rather than the former. The paper shows that patients who are allowed to mobilise weight-bearing in a soft shoe do better than those who are kept non-weight-bearing in a plaster boot for six weeks, which is not surprising. If the authors had wanted to test the stability of the osteotomies themselves it would have been necessary to standardise the postoperative regime. Presumably, they felt that this would have been unethical in view of their earlier biomechanical results, ${ }^{2}$ and those of Shereff, Sobel and Kummer, ${ }^{3}$ but this prejudges the outcome of the study. We doubt if this would have been unethical since several clinical studies $^{4-6}$ of the Mitchell osteotomy have shown a relatively low rate of malunion and transfer metatarsalgia. The foot may have a larger capacity to withstand suboptimal mechanics than in vitro studies suggest.

We suggest that the authors repeat the study comparing the screw-fixed osteotomy with suture fixation in the same postoperative regime, or, if the biomechanics are felt to preclude this, comparison may be made with another osteotomy which is stable on weight-bearing, such as the distal chevron procedure ${ }^{7}$.

P. R. WYKES, FRCS

J. L. BARRIE, FRCS Ed, FRCS Orth

Blackburn Royal Infirmary

Blackburn, UK. 
1. Calder JDF, Hollingdale JP, Pearse MF. Screw versus suture fixation of Mitchell's osteotomy: a prospective randomised trial. J Bone Joint Surg [Br] 1999;81-B:621-4.

2. Calder JDE, Hollingdale JP. Measurement of strength and stability of suture versus AO fixation of Mitchell's osteotomy. The Foot 1997; 7:220-3.

3. Shereff MJ, Sobel MA, Kummer FJ. The stability of fixation of first metatarsal osteotomies. Foot Ankle 1991;11:208-11.

4. Glynn MK, Dunlop JB, Fitzpatrick D. The Mitchell distal metatarsal osteotomy for hallux valgus. J Bone Joint Surg $[\mathrm{Br}]$ 1980;62-B:188-91.

5. Wu KK. Mitchell bunionectomy: an analysis of 430 personal cases plus a review of the literature. J Foot Surg 1987;26:277-92.

6. Canale PB, Aronsson DD, Lamont RL, Manoli A II. The Mitchell procedure for the treatment of adolescent hallux valgus: a long-term study. J Bone Joint Surg [Am] 1993;75-A:1610-8.

7. Crosby LA, Bozarth GR. Fixation comparison for chevron osteotomies. Foot Ankle Int 1998;19:41-3.

\section{Author's reply:}

Sir,

We thank Messrs Wykes and Barrie for their comments.

We agree that it was the early mobilisation of patients after Mitchell's osteotomy which provided the improvement in the early results rather than the screw fixation per se. The purpose of our study was to investigate whether early mobilisation yielded improved results. Sufficient stability at the site of the osteotomy is necessary to allow early mobilisation.

Our previous biomechanical study supported clinical observations that early weight-bearing after suture fixation may lead to unacceptable complications. ${ }^{1}$ It also suggested that screw fixation of Mitchell's osteotomy may provide sufficient stability to allow early mobilisation without the need for splinting.

Our clinical study has shown that early weight-bearing after screw fixation appears to provide sufficient stability both clinically and radiologically. We have shown that such early mobilisation is beneficial during the first six months after operation. In the light of our biomechanical study, comparison with unprotected suture fixation would indeed have been unethical. We believe, however, that comparison with another osteotomy, as suggested by Wykes and Barrie, would introduce a further variable and complicate any interpretation of the results.

J. D. F. CALDER, FRCS

Kew

Surrey, UK.

1. Calder JDF, Hollingdale JP. Measurement of strength and stability of suture versus AO screw fixation of Mitchell's osteotomy: a cadaveric study. The Foot 1997;7:220-3

\section{Nonunion of tibial stress fractures in patients with deformed arthritic knees}

Sir,

I read with interest the article by Sawant et al ${ }^{1}$ entitled 'Nonunion of tibial stress fractures in patients with deformed arthritic knees' in the July 1999 issue. There is, however, an inconsistency which I would like to address. The line diagram (Fig. 2) shows the forces applied to the tibia in a valgus deformity. The authors suggest that a lateral displacement of the mechanical axis will create a 'pivot point' in the lateral compartment of the knee and thus an abnormal tension load on the medial tibia which will cause it to fail in tension. The illustrative radiographs (Fig. 1) show a valgus knee in which the tibia has failed on the compression side. The authors assert that it is the conversion of a tension force to compression which leads to healing of the fracture, but this is not borne out by the illustrations.

May I suggest an alternative explanation, namely that bone abnormalities such as Paget's disease, which is mainly a problem of collagen, fail in tension, and that those in which there is predominantly a problem of mineralisation, such as osteoporosis and osteomalacia, fail in compression. The supraphysiological forces are returned to normal when the deformity is corrected. It is the reduction in overall load rather than a spurious conversion of tension to compression which allows healing.

\section{J. BERNARD, FRCS Ed}

Princess Royal Hospital

Haywards Heath, UK.

1. Sawant MR, Bendall SP, Kavanagh TG, Citron ND. Nonunion of tibial stress fractures in patients with deformed arthritic knees. $J$ Bone Joint Surg [Br] 1999;81-B:663-6.

\section{Author's reply:}

Sir,

We thank Mr Bernard for his comments. Figures 1a and 2 represent a valgus knee with compression forces laterally and tensile forces medially. The issue is how the tibia fractured.

Mr Bernard's main point is that the primary event leading to the fracture is failure of the bone in compression. We do not accept his view.

Biomechanical studies show that for cortical and trabecular bone the regions loaded in tension are at a higher risk of fatigue failure than those loaded in compression. Further, when trabecular bone is loaded beyond the ultimate strength in compression it can still carry a substantial load and failure will not spread. When loaded beyond the ultimate strength in tension, however, the tissue fractures and the surrounding trabeculae must carry the full load. If subsequent failure of the surrounding trabeculae occurs, a cascade effect results and the crack propagates across the bone causing a fracture. Thus local failure of trabecular bone in compression is not likely to lead to failure of whole bone, while local failure in tension could have catastrophic consequences. ${ }^{1}$

In malaligned knees the density of the tibial bone and the compressive strength are increased on the concave side of the deformity in keeping with Wolff's law. ${ }^{2-4}$ In view of this compression, failure of the lateral aspect of the tibia in a valgus knee is less likely.

Tensile failure is the primary event leading to failure. We accept that once this has occurred it may lead to secondary lateral trabecular collapse, but not as a primary event as postulated by $\mathrm{Mr}$ Bernard.

Figure 1a does show a medial fracture line, although we agree that it is not very obvious.

M. SAWANT, FRCS Orth Ipswich Hospital NHS Trust Ipswich, UK.

1. Kaplan FS, Hayes WC, Keaveny TM, et al. Form and function of bone. In: Simon SR, ed. Orthopaedic basic science. American Academy of Orthopaedic Surgeons, 1994:127-84.

2. Hvid I. Trabecular bone strength at the knee. Clin Orthop 1988;227:210-21.

3. Bauer GCH, Insall J, Koshino T. Tibial osteotomy in gonarthrosis (osteoarthritis of the knee). J Bone Joint Surg [Am] 1969;51-A:154563.

4. Behrens JC, Walker PS, Shoji H. Variations in strength and structure of cancellous bone at the knee. J Biomech 1974;7:202. 